\title{
The SNARE Vti1a- $\beta$ Is Localized to Small Synaptic Vesicles and Participates in a Novel SNARE Complex
}

\author{
Wolfram Antonin, ${ }^{2}$ Dietmar Riedel, ${ }^{2}$ and Gabriele Fischer von Mollard1 \\ 1Zentrum Biochemie und Molekulare Zellbiologie, Abteilung Biochemie II, Universität Göttingen, 37073 Göttingen, \\ Germany, and 2Abteilung Neurobiologie, Max-Planck Institut für Biophysikalische Chemie, 37077 Göttingen, Germany
}

\begin{abstract}
Specific soluble $N$-ethylmaleimide-sensitive factor attachment protein (SNAP) receptor (SNARE) proteins are required for different membrane transport steps. The SNARE Vti1a has been colocalized with Golgi markers and Vti1b with Golgi and the trans-Golgi network or endosomal markers in fibroblast cell lines. Here we study the distribution of Vti1a and Vti1b in brain. Vti1b was found in synaptic vesicles but was not enriched in this organelle. A brain-specific splice variant of Vti1a was identified that had an insertion of seven amino acid residues next to the putative SNARE-interacting helix. This Vti1a- $\beta$ was enriched in small synaptic vesicles and clathrin-coated vesicles isolated from nerve terminals. Vti1a- $\beta$ also copurified with the synaptic vesicle R-SNARE synaptobrevin during immunoisolation of syn-
\end{abstract}

aptic vesicles and endosomes. Therefore, both synaptobrevin and Vti1a- $\beta$ are integral parts of synaptic vesicles throughout their life cycle. Vti1a- $\beta$ was part of a SNARE complex in nerve terminals, which bound $N$-ethylmaleimide-sensitive factor and $\alpha$-SNAP. This SNARE complex was different from the exocytic SNARE complex because Vti1a- $\beta$ was not coimmunoprecipitated with syntaxin 1 or SNAP-25. These data suggest that Vti1a- $\beta$ does not function in exocytosis but in a separate SNARE complex in a membrane fusion step during recycling or biogenesis of synaptic vesicles.

Key words: SNARE; synaptic vesicle; clathrin-coated vesicle; endosome; Vti1; nerve terminal; membrane traffic
Transport between different organelles requires complex formation between specific members of the $N$-ethylmaleimide-sensitive factor attachment protein (SNAP) receptor (SNARE) protein family on both transport vesicles ( $\mathrm{v}$-SNARE) and target membranes (t-SNARE) (Rothman, 1994). SNARE proteins have common structural features. Most of them contain a C-terminal membrane anchor. They interact with each other via predicted coiled coil domains close to the membrane. These SNARE proteins are conserved in evolution, numbering 21 family members in yeast and so far over 35 in mammals (Jahn and Sudhof, 1999) The SNARE complex required for exocytosis of synaptic vesicles has been studied extensively. It consists of the synaptic vesicle v-SNARE synaptobrevin and the plasma membrane t-SNAREs syntaxin 1 and SNAP-25. Synaptobrevin and syntaxin contribute one helix and SNAP-25 two helices to a parallel four-helix bundle (Sutton et al., 1998). A conserved arginine in synaptobrevin interacts with the three glutamines from the t-SNAREs in a central layer of the SNARE complex. The SNARE complex required for exocytosis in yeast also consists of a four-helix bundle with interactions between one arginine and three glutamine containing helices (Rossi et al., 1997), suggesting that this is a common feature of SNARE complexes (Fasshauer et al., 1998b). Therefore, SNARE proteins have been reclassified as R-SNAREs (arginine) or Q-SNAREs (glutamine). All t-SNAREs are Q-SNAREs, whereas v-SNAREs are either R-SNAREs or Q-SNAREs.

Received Feb. 2, 2000; revised May 10, 2000; accepted May 15, 2000.

This work was supported by grants from the Volkswagen Stiftung and the Deutsche Forschungsgemeinschaft SFB 532, TP B6, and TP B7. We thank B. Köhler and M. Druminski for excellent technical assistance and S. Lausmann for preparing and staining the hippocampal sections. We also thank Dr. C. Rosenmund (Max-Planck Institut für Biophysikalische Chemie, Göttingen, Germany) for generating the neuronal cell cultures and $\mathrm{M}$. Margittai and S. Pabst for providing purified, recombinant NSF and $\alpha$-SNAP. We acknowledge Dr. C. Barnstable (New Haven, CT) and Dr. E. Hartmann (Universität Göttingen, Göttingen, Germany) for the kind gift of antibodies and S. Whiteheart and J. E. Rothman (Sloan-Kettering Center, New York, NY) for the kind gift of expression constructs. We are grateful to Dr. K. von Figura and Dr. R. Jahn for their support, stimulating discussions, and critical reading of this manuscript.

Correspondence should be addressed to Gabriele Fischer von Mollard, Zentrum Biochemie und Molekulare Zellbiologie, Abteilung Biochemie II, Universität Göttingen, Heinrich-Düker Weg 12, 37073 Göttingen, Germany. E-mail: mollard@uni-bc2. gwdg.de.

Copyright (C) 2000 Society for Neuroscience $0270-6474 / 00 / 205724-09 \$ 15.00 / 0$
The composition of SNARE complexes required for intracellular traffic is less clear. A single SNARE can be part of different complexes. Yeast Vtilp interacts with the cis-Golgi t-SNARE Sed5p in retrograde traffic to the cis-Golgi (Lupashin et al., 1997), with the endosomal t-SNARE Pep12p in traffic from the Golgi to the endosome (Fischer von Mollard et al., 1997) and with the vacuolar t-SNARE Vam3p in biosynthetic transport pathways to the vacuole/lysosome (Fischer von Mollard and Stevens, 1999) and in homotypic vacuolar fusion (Ungermann et al., 1999). Vti1p binds to the t-SNAREs Tlg1p (early endosome) and Tlg2p [transGolgi network (TGN)] (Holthuis et al., 1998). Two proteins related to yeast Vti1p were identified in mammals (Lupashin et al., 1997; Fischer von Mollard and Stevens, 1998). Mouse Vti1a and Vti1b share only $30 \%$ amino acid identity and have a similar degree of homology with the yeast protein (33 and 27\%). Tagged Vti1b/Vti1rp1 overlapped with Golgi and TGN proteins (Advani et al., 1998). Vti1-rp1/Vti1b was found in endosomes according to unpublished results mentioned by Xu et al. (1998). Vti1-rp2/Vti1a was localized to the Golgi apparatus. Vtila could be coimmunoprecipitated with the cis-Golgi t-SNARE syntaxin 5 and the TGN syntaxin 6. Antibodies against Vti1a block intra-Golgi traffic (Xu et al., 1998).

Here we describe a brain-specific splice variant of Vtila that is localized to synaptic vesicles. This Vti1a- $\beta$ is not part of the exocytic SNARE complex but may function in a novel SNARE complex required for synaptic vesicle recycling or biogenesis.

\section{MATERIALS AND METHODS}

Materials. Reagents were used from the following sources: enzymes for DNA manipulations from New England Biolabs (Beverly, MA); secondary antibodies from Jackson ImmunoResearch (West Grove, PA); Eupergit C1Z methacrylate microbeads from Röhm Pharma (Darmstadt, Germany); glutathione (GSH)-Sepharose 6B and cyanogen bromide (CNBr)-Sepharose 4B (Amer-sham Pharmacia Biotech, Uppsala, Sweden); and Ni-NTA agarose from Qiagen (Hilden, Germany). All other reagents were purchased from Sigma (Deisenhofen, Germany). Plasmid manipulations were performed in the Echerichia coli strain XL1Blue.

$N$-ethylmaleimide-sensitive factor (NSF) and $\alpha$-SNAP in pQE-9 plasmids encoding for His6-tagged fusion proteins were kindly provided by $\mathrm{S}$ Whiteheart and J. E. Rothman (Sloan-Kettering Center, New York, NY).

Cloning of rat Vtila and Vtila- $\beta$. Sequence data from rat expressed sequence tags (ESTs) (GenBank accession numbers AI010508, AI227646, and AI555622) were used to assemble the sequence of rat Vtila. Oligonucleotide primers annealing a few base pairs upstream of the start codon 
and downstream of the stop codon of rat Vtila (GGG GTA CCG GAG CTG CCA TGT CAG and CGG GAT CCG CCT CAG TGT CCT CTG AC) were used to PCR amplify DNA from rat lung and rat cerebellum cDNA $\lambda$ ZAPII libraries (Stratagene, La Jolla, CA). The PCR products derived from cerebellum cDNA were reamplified using the same primers and cloned into pGEM-Teasy (Promega, Madison, WI). The nucleotide sequences of inserts of three clones with slightly smaller and three clones with slightly larger inserts were determined. The smaller clones encoded Vti1a and the larger clones Vti1a- $\beta$ with an insertion of 21 base pairs.

Reverse transcription-PCR. Total RNA was isolated from different rat tissues (cerebellum, cortex, hippocampus, lung, liver, kidney, and spleen $200 \mathrm{mg}$ each) using TRIZOL reagent (Life Technologies, Rockville, MD) following the instructions of the manufacturer. RNA $(5 \mu \mathrm{g})$ was used for an RT-PCR reaction using the Superscript II kit (Life Technologies) following the instructions of the manufacturer in a total volume of $20 \mu \mathrm{l}$. Ten percent of the products of the RT-PCR were used as a template for the specific PCRs. The three oligonucleotides gagaaccagagggcacatc (Vti1a, annealing with codons $110-116$ and therefore only with Vtila), ttgataaaattacgtgaggag (Vti1a- $\beta$, annealing with the vti1- $\beta$ specific codons 115-121), and gagaagaagcaaatggttg (MB7, annealing with codons 33-38) were used as forward primers each in combination with the oligonucleotide gggatcctagcggttttggatgattcttc (rVbsol, annealing with codons 187-180) as a reverse primer.

Protein purification. Recombinant NSF and $\alpha$-SNAP were purified as described previously (Hanson et al., 1995). Recombinant glutathione $S$-transferase (GST)-rat Vti1a [amino acids (aa) 1-114] and GST-rat Vti1a (aa 115-192) were purified using GSH-Sepharose 6B following the instructions of the manufacturer.

Antibodies. Antisera were raised in rabbits against a fusion protein containing GST and the amino acids $1-207$ of mouse Vti1b (pBK9) or amino acids 1-187 of mouse Vti1a (pBK10) purified from E. coli. The antisera were affinity purified with Affigel 10 columns with covalently bound 6 His-mVti1b (amino acids 1-207, pBK38) or 6His-mVti1a (amino acids 1-187, pBK39), respectively, for immunofluorescence. Vtila antiserum specific for the $\mathrm{N}$-terminal or $\mathrm{C}$-terminal region of the protein was affinity-purified using recombinant GST-rat Vti1a (aa 1-114) or GST-rat Vti1a (aa 115-192), respectively, coupled to CNBr-Sepharose 4B. The affinity-purified antisera were specific for their targets [the $\mathrm{C}$-terminal antiserum did not recognize GST-Vtila (aa 1-114) and the N-terminal antiserum did not detect GST-Vtila (aa 115-192)].

The following antibodies were described previously: synaptophysin (monoclonal antibody, C17.2) (Jahn et al., 1985); rab5 (monoclonal antibody, Cl 621.3) (Fischer von Mollard et al., 1994); rab5 (rabbit antiserum R6) and rab3a (monoclonal antibody, C142.2) (Matteoli et al., 1991); SNAP-25 (C171.2) (Bruns et al., 1997); and synaptobrevin (monoclonal antibody, C169.1). The following antibodies were kind gifts: syntaxin 1 (monoclonal antibody HPC-1; provided by Dr. C. Barnstable, New Haven, CT) (Barnstable et al., 1985); and Sec61 $\alpha$ (rabbit serum; provided by Dr. E. Hartmann, Göttingen, Germany). Commercial sources were used for the following antibodies: secretory carrier membrane protein (SCAMP) (rabbit serum; Synaptic Systems, Göttingen, Germany); and syntaxin 6 (monoclonal antibody; Transduction Laboratories, Lexington, KY).

Immunofluorescence. Adult female Sprague Dawley rats were anesthetized, perfused, and post-fixed as described previously (Mugnaini and Dahl, 1983), with modifications. Briefly, a rat was perfused transcardially with ice-cold $0.9 \% \mathrm{NaCl}$, followed by fixative ( $4 \%$ formaline, $0.9 \% \mathrm{NaCl}$, and $0.5 \% \mathrm{ZnCl}_{2}$ ). The brain was dissected and immersed in the same fixative overnight at $4^{\circ} \mathrm{C}$. After rinse in $0.1 \mathrm{M}$ Tris- $\mathrm{HCl}, \mathrm{pH} 7.2$, the tissue was incubated overnight in $20 \%$ sucrose containing $0.1 \mathrm{M}$ Tris- $\mathrm{HCl}, \mathrm{pH} 7.2$, and then sectioned on a cryostat at $8 \mu \mathrm{m}$. The sections were mounted on poly-L-lysine-coated glass slides and incubated in PBS containing 3\% goat serum and $0.3 \%$ Triton X-100 (GSDB) for $30 \mathrm{~min}$. The sections were incubated overnight with the respective antibodies, washed with PBS, and incubated for $1 \mathrm{hr}$ at room temperature with secondary antibodies (Cy2conjugated goat anti-mouse antibody and Cy3-conjugated goat anti-rabbit antibody (Jackson ImmunoResearch) in GSDB. After washing with PBS, the sections were coverslipped with mounting solution (Dako, Glostrup, Denmark) and analyzed with a confocal microscope (LSM-410-invert; Zeiss, Göttingen, Germany).

Culturing of neurons from the hippocampi of neonatal rats (Sprague Dawley) was done as described previously (Rosenmund et al., 1995). After 3 weeks in culture, the cells were processed for immunofluorescence as described previously (Hannah et al., 1998) using Triton X-100 as detergent. The staining was analyzed with a confocal microscope (LSM-410-invert; Zeiss).

Electron microscopy. For immunogold labeling, purified synaptic vesicles (as described below) were adsorbed to glow discharged nickel grids. Thereafter, labeling with diluted respective antibodies [synaptophsin antiserum (G 95), 1:100, Vti1a affinity-purified serum, 1:50)] and $10 \mathrm{~nm}$ goat anti-rabbit IgG gold conjugates diluted at 1:100 in 1\% BSA in phosphate buffer were performed. The samples were post-fixed for 10 min with $2 \%$ glutharaldehyde in phosphate buffer, washed with $\mathrm{H}_{2} \mathrm{O}$, rinsed with 3 drops of $1 \%$ uranyl acetate, and immediately dried with filter paper.

Isolation of organelles. Small synaptic vesicles were purified as described previously (Huttner et al., 1983). Clathrin-coated vesicles were purified from rat brain synaptosomes as described previously (Maycox et al., 1992).

For immunoisolation of organelles, monoclonal antibodies Cl 69.1 (anti-

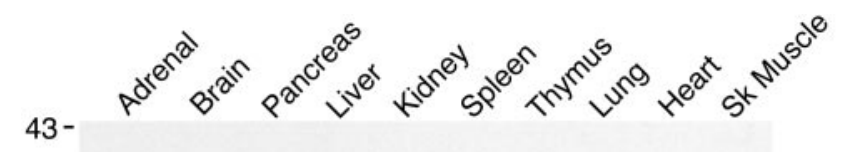

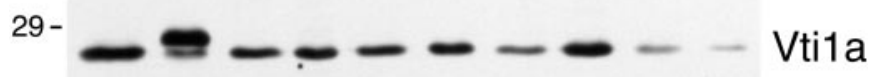

$18-$

43-

29-

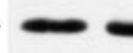

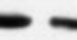

$-$

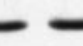

$-$

Vti1b

$18-$

Figure 1. Vti1a and Vti1b were expressed in all tissues. Homogenates were prepared from the indicated mouse tissues, and $20 \mu \mathrm{g}$ separated by SDSPAGE Western blots were stained with antisera against Vtila or Vtilb. The Vti1a antiserum recognized a ubiquitous protein of $27 \mathrm{kDa}$ and an additional slightly larger brain-specific band. Vti1b antiserum bound to a single band of $29 \mathrm{kDa}$.

synaptobrevin), Cl 42.2 (anti-rab3a) and $\mathrm{Cl} 621.3$ (anti-rab5) were covalently coupled to Eupergit $\mathrm{C} 1 \mathrm{Z}$ methacrylate microbeads as described previously (Burger et al., 1989). Rat brain was homogenized in $25 \mathrm{ml}$ of homogenization buffer [ $320 \mathrm{~mm}$ sucrose, $5 \mathrm{~mm}$ HEPES, pH 7.4, $1 \mathrm{~mm}$ EDTA, $0.1 \mathrm{~mm}$ GTP $\gamma \mathrm{S}$, and protease inhibitors $(10 \mu \mathrm{g} / \mathrm{ml}$ soybean trypsin inhibitor, $1 \mu \mathrm{g} / \mathrm{ml}$ pepstatin, $11 \mu \mathrm{g} / \mathrm{ml}$ benzamidine, $1 \mu \mathrm{g} / \mathrm{ml}$ antipain, 1 $\mu \mathrm{g} / \mathrm{ml}$ leupeptin, and $0.1 \mathrm{~mm}$ phenylmethylsulfonyl fluoride)] using a glass Teflon homogenizer (10 strokes, $1000 \mathrm{rpm})$. Postnuclear supernatant (PNS) was generated by centrifugation at $1000 \times g_{\text {a }}$ for $10 \mathrm{~min}$. PNS was further centrifuged for $30 \mathrm{~min}$ at $50.000 \times g_{\text {av }}$ to remove myelin increasing the unspecific binding to the beads. The resulting supernatant $(800 \mu \mathrm{g}$ of protein) was incubated in $800 \mu \mathrm{l}$ of homogenization buffer with $20 \mu \mathrm{l}$ of the appropriate beads for $1 \mathrm{hr}$ at $4^{\circ} \mathrm{C}$. The incubation mixture was layered on top of a sucrose cushion $(0.5 \mathrm{ml}, 0.8 \mathrm{M})$ and centrifuged for $5 \mathrm{~min}$ at $4600 \times$ $g_{\mathrm{av}}$. The supernatants were centrif uged for $30 \mathrm{~min}$ at $200,000 \times g_{\text {av }}$ at $4^{\circ} \mathrm{C}$ using a Beckman TLA120.2 rotor to sediment nonbound membranes. The bead pellets were washed five times with PBS. Aliquots of each sample as well as the starting PNS were analyzed by SDS-PAGE and immunoblotting.

Immunoprecipitation. A synaptosomal fraction (P2) was solubilized in extraction buffer (50 mM Tris-HCl, $\mathrm{pH} 7.4,150 \mathrm{~mm} \mathrm{NaCl}, 1 \mathrm{~mm}$ EDTA, 0.1 mM phenylmethylsulfonyl fluoride, and $1 \%$ Triton X-100) at a final protein concentration of $0.5 \mathrm{mg} / \mathrm{ml}$ for $1 \mathrm{hr}$ at $4^{\circ} \mathrm{C}$. Lysates were clarified by centrif ugation at $200,000 \times g$ for $10 \mathrm{~min}$. After transfer of the supernatant to a fresh tube, immunoprecipitations were conducted for $2 \mathrm{hr}$ at $4^{\circ} \mathrm{C}$ with monoclonal antibodies against syntaxin 6, syntaxin 1 (HPC-1), SNAP-25 (71.2), synaptobrevin (69.1), or affinity-purified antibody specific for Vti1a. Antibodies were bound to Protein A-Sepharose beads (Amersham Pharmacia Biotech) for $60 \mathrm{~min}$, sedimented, and washed eight times with extraction buffer. The supernatants were precipitated (Wessel and Flügge, 1984). The immunoprecipitates and $30 \%$ of the precipitated supernatants were analyzed by SDS-PAGE and immunoblotting using the above antibodies. In the case of the detection of SNAP-25, an anti-mouse Fc antibody was used as a secondary antibody to exclude a cross-reactivity with the light chain of the antibodies used for immunoprecipitation.

Binding of NSF and $\alpha$-SNAP to SNARE complexes. Detection of a $20 \mathrm{~S}$ complex containing Vti1a- $\beta$ was done as described previously (Söllner et al., 1993a), using the LP2 fraction from rat (high-speed membrane fraction of lysed synaptosomes) as starting material instead of bovine brain membranes. In brief, the LP2 fraction $(0.5 \mathrm{mg} / \mathrm{ml}$ final protein concentration was solubilized in $20 \mathrm{~mm}$ HEPES, pH 7.4, $100 \mathrm{~mm} \mathrm{KCl}, 1 \mathrm{~mm}$ EDTA, and $0.5 \%$ Triton $\mathrm{X}-100$ at $4^{\circ} \mathrm{C}$ for $1 \mathrm{hr}$. Insoluble material was removed by centrifugation at $200,000 \times g_{\text {av }}$ for $10 \mathrm{~min}$. The supernatant $(1 \mathrm{ml})$ was incubated with recombinant NSF $(0.3 \mu \mathrm{M})$ and $\alpha$-SNAP $(0.9 \mu \mathrm{M})$ for $1 \mathrm{hr}$ at $4^{\circ} \mathrm{C}$ and then layered on top of a $10-35 \%(\mathrm{w} / \mathrm{v})$ glycerol gradient containing the same buffer as above and subjected to centrifugation for 19 $\mathrm{hr}$ in an SW41 rotor (Beckman) at 40,000 rpm at $4^{\circ} \mathrm{C}$. Fractions $(1 \mathrm{ml})$ were collected, and the proteins were precipitated by trichloroacetic acids, separated by SDS-PAGE, and electrotransferred to nitrocellulose. The blots were immunodecorated with the indicated antibodies. In a control reaction, NSF and $\alpha$-SNAP were omitted.

SNARE complex disassembly reaction. LP2 fractions (high-speed membrane fraction of lysed synaptosomes, $0.5 \mathrm{mg} / \mathrm{ml}$ final concentration of protein) were preincubated with $3 \mu \mathrm{M} \mathrm{NSF}, 9 \mu \mathrm{M} \alpha$-SNAP, $3 \mathrm{mM} \mathrm{MgCl}_{2}$, 

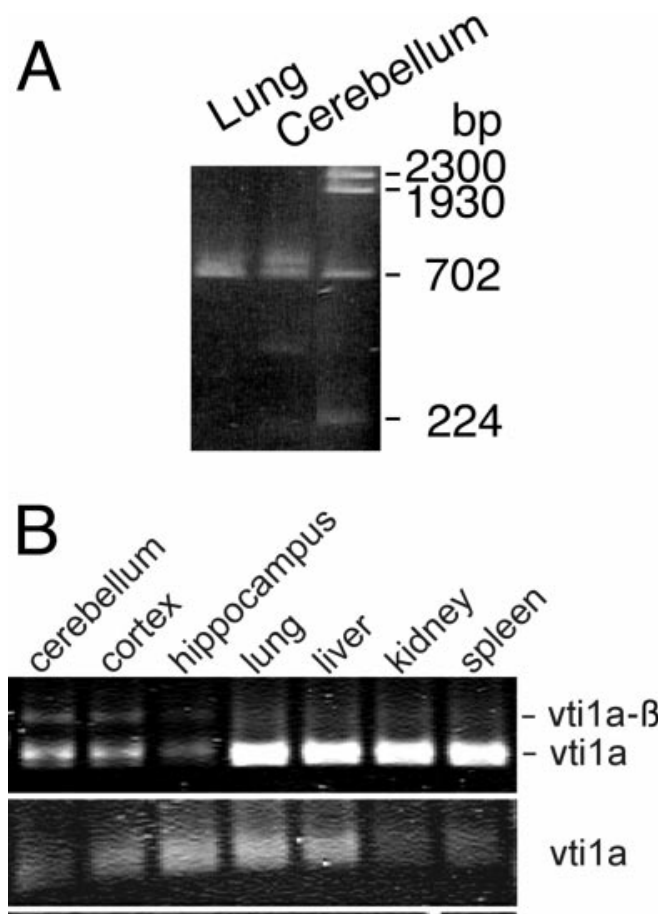

teas valia-ß

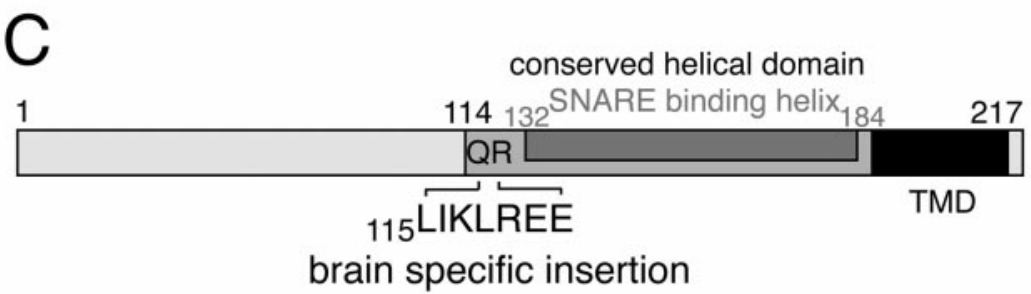

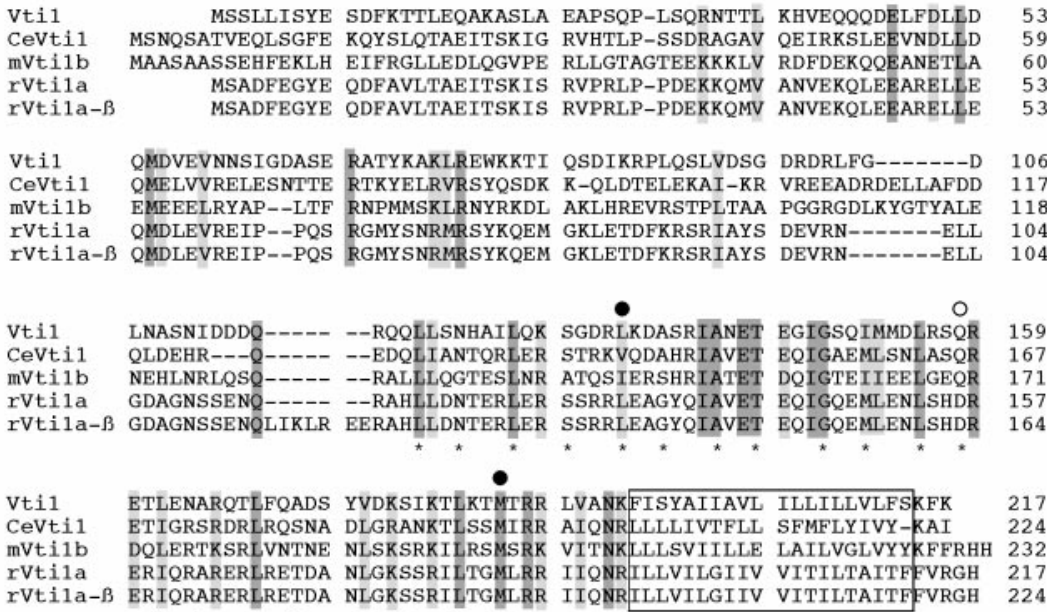

Figure 2. The brain-specific splice variant Vti1a- $\beta$ had an insertion of seven amino acid residues. $A$, A single band was PCR-amplified from a lung cDNA library, a double band from a cerebellum cDNA library using primers specific for Vti1a. The slightly larger band encoded Vtila- $\beta$ with a insertion of seven amino acids after Q114. B, Expression pattern of Vti1a and Vti1a- $\beta$ in different tissues. RT-PCRs were performed using primer pairs amplifying both Vti1a and Vti1a- $\beta$ (expected sizes, 511 and $490 \mathrm{bp}$; top), Vti1a only (forward primer annealing with codons 110-116, 265 bp; middle), or Vti1a- $\beta$ only (forward primer annealing with Vtila- $\beta$-specific codons 115-121, $253 \mathrm{bp}$; bottom). Vtila was amplified from all tissues examined. Vtila- $\beta$ was amplified from the neuronal tissues cerebellum, cortex, and hippocampus, but not from lung, liver, kidney, or spleen. C, Alignment of Saccharomyces cerevisiae Vti1p, the C-terminal part of a predicted $C$. elegans protein (GenBank accession number CAB16506), mouse Vtilb, rat Vti1a (GenBank accession number AF262221), and rat Vti1a- $\beta$ (GenBank accession number AF262222). Filled circles indicate the beginning and end of the predicted SNARE-interacting helix (SNARE motif). The open circle marks the position of the conserved glutamine or aspartate residue in layer 0, and asterisks indicate hydrophobic positions in the heptade repeats.

and $3 \mathrm{~mm}$ ATP in $50 \mathrm{~mm}$ HEPES, pH 7.4, for $10 \mathrm{~min}$ at $30^{\circ} \mathrm{C}$. Then, trypsin was added to a final concentration of $0.05 \mathrm{mg} / \mathrm{ml}$, and the samples were incubated for another $15 \mathrm{~min}$ at $30^{\circ} \mathrm{C}$. Reaction was stopped by adding soybean trypsin inhibitor and phenylmethylsulfonyl fluoride to a final concentration of $100 \mu \mathrm{g} / \mathrm{ml}$ and $1 \mathrm{~mm}$, respectively. SDS sample buffer was added, and the samples were heated immediately for $5 \mathrm{~min}$ at $100^{\circ} \mathrm{C}$. As a control, the reaction was either performed in the absence of NSF and $\alpha$-SNAP or the ATPase activity of NSF was abolished by replacing ATP with $3 \mathrm{~mm}$ ATP $\gamma \mathrm{S}$ or $\mathrm{MgCl}_{2}$ with $10 \mathrm{~mm}$ EDTA, respectively.

\section{RESULTS}

\section{Identification of a brain-specific Vti1a splice variant}

For the characterization of Vti1a and Vti1b proteins, we generated polyclonal antibodies in rabbits using purified recombinant fusion proteins as antigens (see Materials and Methods for details). Both antisera reacted with single bands of 27 (Vtila) and 29 (Vti1b) $\mathrm{kDa}$, respectively, close to the predicted molecular weight of the proteins. A tissue survey by immunoblotting of homogenate extracts revealed that both Vtila and Vtilb are widely distributed in all tissues examined (Fig. 1). In brain extracts, the Vti1a-specific antiserum recognized an additional band with a slightly lower mobility that was not observed in other tissues. To determine whether this higher molecular weight band is produced from a splice variant of the Vtila mRNA, the coding sequences of Vtila were amplified from lung and cerebellum rat cDNA libraries (Fig. $2 A)$. A single band was amplified from the lung cDNA library. In contrast, two bands, one band of slightly lower mobility than the PCR product from lung, were amplified from the cerebellum

Figure 3. Vtila localized to the cell body as well as to nerve terminals of hippocampal neurons. Cultured hippocampal neurons were double stained for Vti1a or Vti1b and synaptobrevin. Vtila and Vtilb were found in the cell body. In addition, Vtila colocalized with synaptobrevin in nerve terminals. Scale bar, $20 \mu \mathrm{M}$.

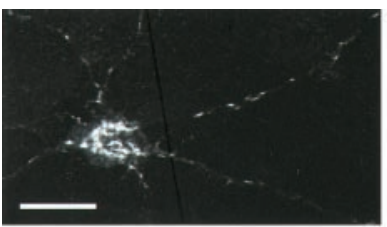

\section{Vti1a}

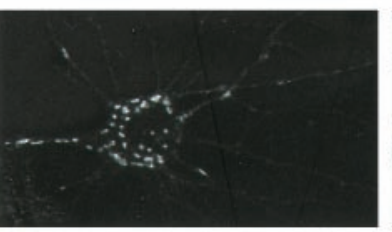

Vti1b

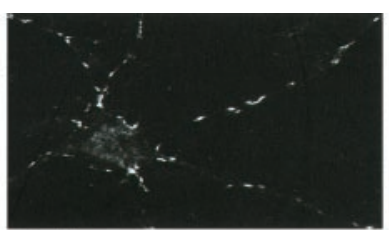

Syb

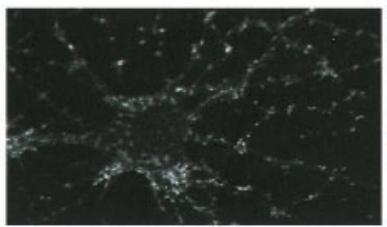

Syb

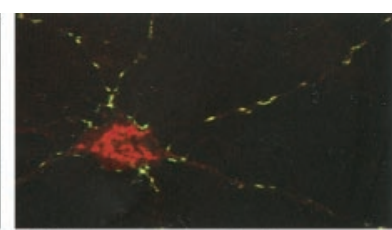

Vti1a red Syb green

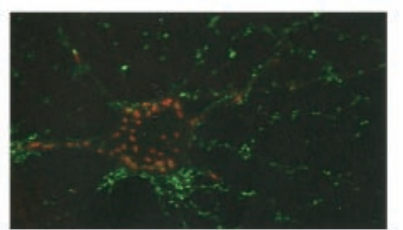

Vti1b red Syb green 


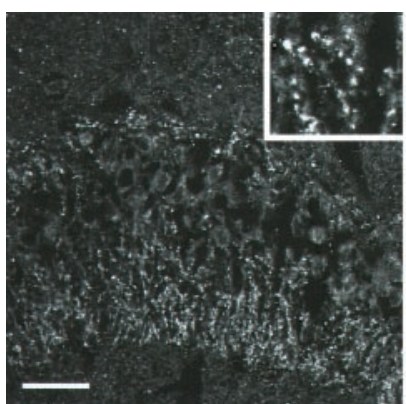

Vti1a

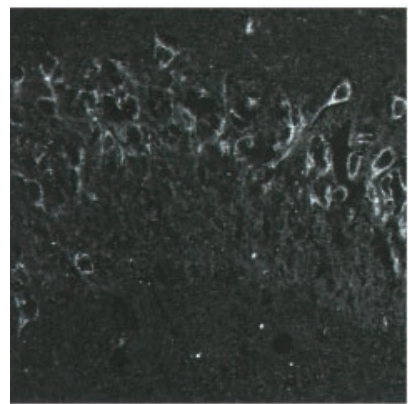

Vti1b

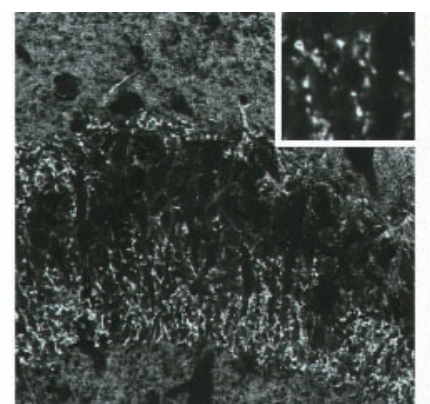

Syb

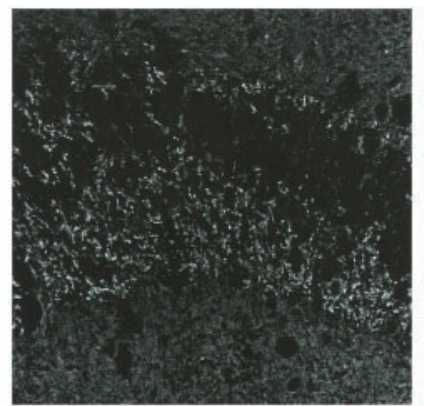

Syb

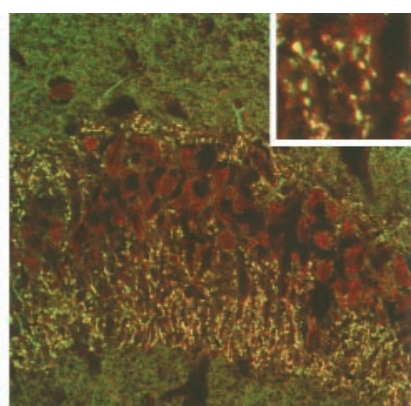

Vti1a red Syb green

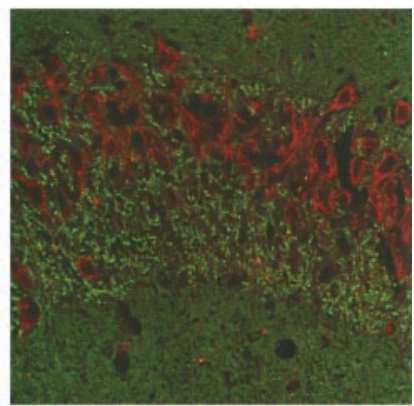

Vti1b red Syb green
Figure 4. Vtila localized to the cell body as well as to mossy fiber terminals in hippocampal sections. Rat hippocampal sections were double stained for Vti1a or Vtilb and synaptobrevin. Vti1a and Vti1b were found in the cell bodies of pyramidal cells. Vtila also colocalized with synaptobrevin in mossy fiber nerve terminals. The insets in the top panels show a threefold magnification of an area from the mossy fiber nerve terminals. Scale bar, $30 \mu \mathrm{M}$.
cDNA. Both bands were cloned into plasmids, and the inserts were sequenced. The top band corresponded to rat Vti1a, except for an insertion of 21 nucleotides. This sequence encoded the brainspecific splice variant Vtila- $\beta$ with the insertion of the amino acid sequence LIKLREE C-terminal of residue 114. Residue 114 is located at the beginning of a domain, which is conserved among the Vti1 proteins from different species and is predicted to form an $\alpha$-helix (Fig. 2C). Alignment with the different SNAREs predicts that the SNARE-interacting helix (SNARE motif) of Vtila starts at residue 132. The bottom band encoded the rat Vtila.

To further analyze the expression patterns of both splice variants, RT-PCRs were performed with RNAs isolated from different rat tissues. Primer pairs were designed to amplify both splice variants (Fig. $2 B$, top), Vtila only (middle), or Vtia- $\beta$ only (bottom). Vtila was amplified from all tissues examined. Vti1a- $\beta$ was expressed in the neuronal tissues cerebellum, cortex, and hippocam-

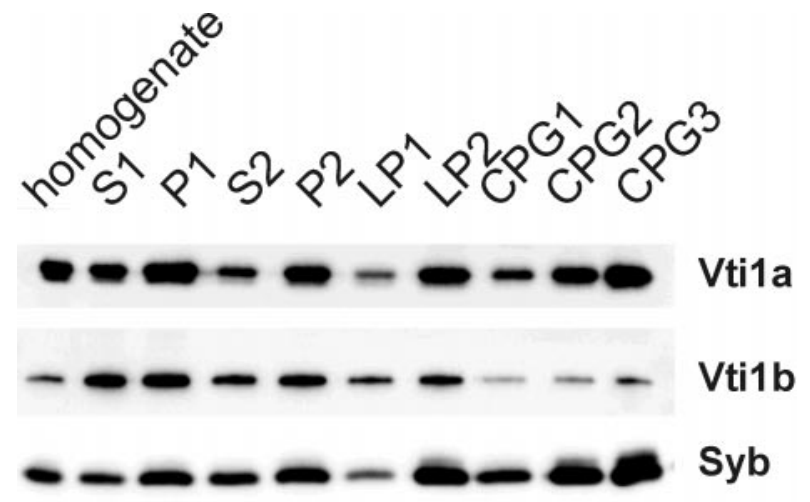

Figure 5. Vtila- $\beta$ copurified with synaptic vesicles. Synaptosomes (P2) were isolated from rat brain homogenate $(H)$. The synaptosomes were osmotically lysed and separated into a low-speed membrane fraction (LP1) containing synaptic plasma membranes and a high-speed pellet $(L P 2)$ with synaptic vesicles. The synaptic vesicles were further purified by sucrose density gradient centrifugation and chromatography on a CPG column yielding the highly enriched fraction CPG3. Vtila- $\beta$ copurified with the synaptic vesicle marker synaptobrevin $(S y b)$. Vtilb was present in synaptic vesicles but was not enriched compared with homogenate. pus, but not in lung, liver, kidney, or spleen. These data confirm that Vtila- $\beta$ is a brain-specific splice variant.

Mouse and rat Vti1a, as well as a human Vti1a assembled from the EST database, have an aspartate residue at position 156 instead of the conserved glutamine found in the center of the SNARE helix in other Q-SNAREs and all other Vti1 proteins. Still, an aspartate residue would be able to form a strong ionic interaction with an arginine residue in the center of the SNARE motif. Rat and mouse Vti1a were $96 \%$ identical in their amino acid sequence. Conserved exchanges were found in nine amino acid residues $(\mathrm{D} / \mathrm{E}, \mathrm{R} / \mathrm{K}, \mathrm{A} / \mathrm{S}$, and $\mathrm{A} / \mathrm{T})$. The $\mathrm{C}$-terminal part of a predicted Caenorhabditis elegans protein (GenBank accession number CAB16506) had a high degree of homology with mouse Vtila (41\% amino acid identity) and a lower degree of homology with mouse Vti1b (25\% amino acid identity).

\section{Vti1a localized to cell bodies and nerve terminals in neurons}

In previous studies, Vtila was localized to the Golgi apparatus of fibroblasts (Xu et al., 1998). The localization of Vti1b is less clear because it was found to colocalize with either Golgi and TGN (Advani et al., 1998) or with endosomal markers (Xu et al., 1998). To investigate the localization of both proteins in neurons, we performed indirect immunofluorescence on both cultured hippocampal neurons and hippocampal tissue sections. In cultured neurons, Vtilb was localized to large cisternae in the cell body and to a few structures in processes close to the cell bodies (Fig. 3). No overlap was found between the staining of Vti1b and of synaptobrevin 2, an R-SNARE specific for synaptic vesicles. In contrast, the staining pattern for Vtila was different. Vtila was also found in the perinuclear region of the cell body, but Vti1a and Vti1b stained different structures. An additional pool of Vtila was observed in the processes and overlapped there with synaptobrevin in the nerve terminals. To further analyze the subcellular distribution, hippocampal sections were stained (Fig. 4). Again, Vti1b antiserum stained the cell bodies of pyramidal cells but not the nerve terminals of the mossy fibers. The staining for Vti1b and synaptobrevin did not overlap. Vti1a and synaptobrevin clearly colocalized in the large nerve terminals of the mossy fibers. Vtila was also found in the cell bodies of pyramidal cells. These data indicate that a subfraction of Vtila was localized to nerve terminals. 
Figure 6. Vti1a was localized to synaptic vesicles using immunogold electron microscopy. The CPG3 fraction was adsorbed to coated grids and incubated with antisera against the synaptic vesicle marker synaptophysin $(A)$, against Vti1a $(B)$, or without antiserum $(C)$ followed by $10 \mathrm{~nm}$ goat anti-rabbit IgG gold conjugates and negative staining. Scale bar, $500 \mathrm{~nm}$.
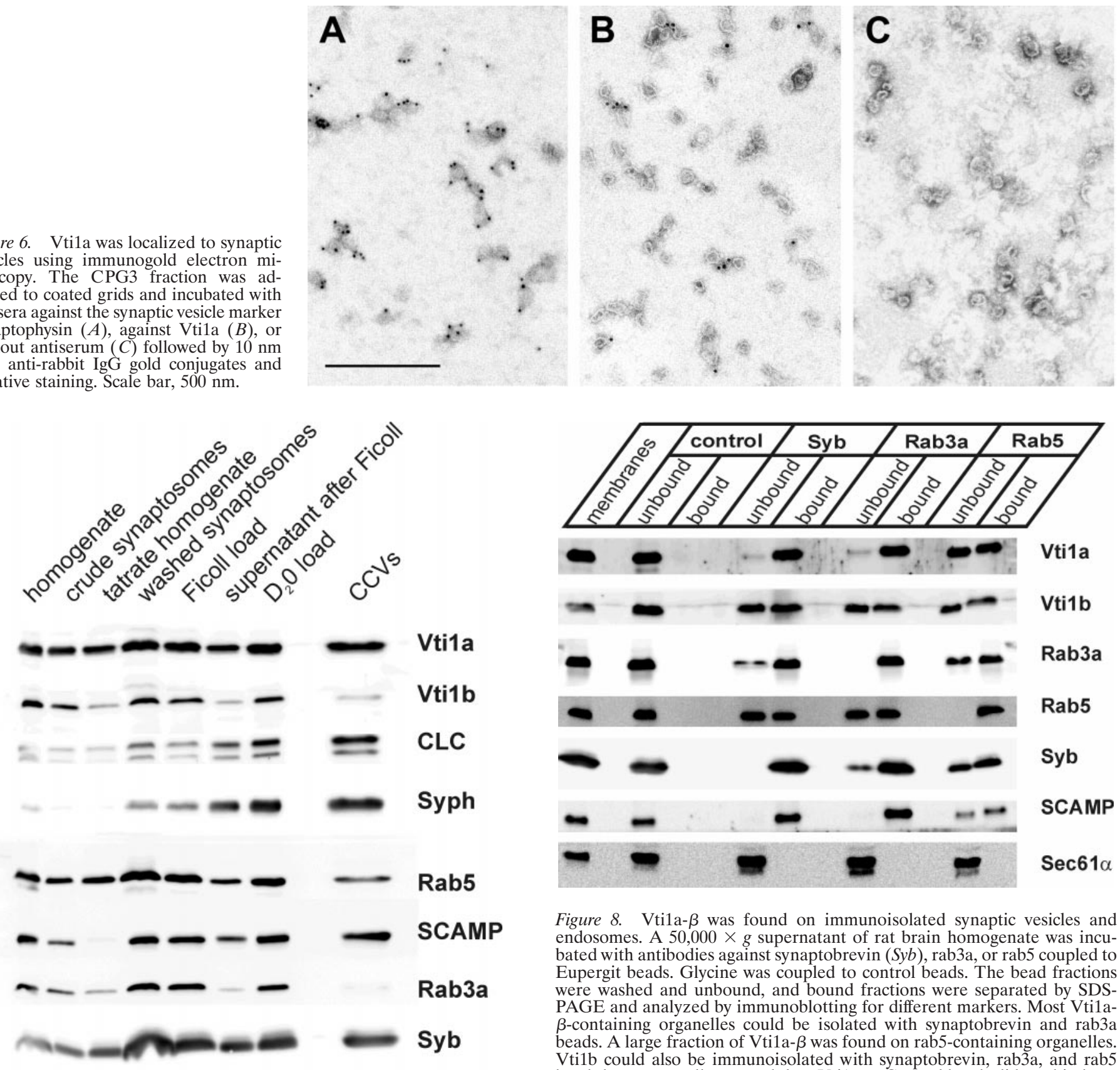

Figure 8. Vti1a- $\beta$ was found on immunoisolated synaptic vesicles and endosomes. A 50,000 $\times g$ supernatant of rat brain homogenate was incubated with antibodies against synaptobrevin $(S y b)$, rab3a, or rab5 coupled to Eupergit beads. Glycine was coupled to control beads. The bead fractions were washed and unbound, and bound fractions were separated by SDSPAGE and analyzed by immunoblotting for different markers. Most Vti1a$\beta$-containing organelles could be isolated with synaptobrevin and rab3a beads. A large fraction of Vti1a- $\beta$ was found on rab5-containing organelles. Vti1b could also be immunoisolated with synaptobrevin, rab3a, and rab5 beads but to a smaller extend than Vti1a- $\beta$. Control beads did not bind any proteins, and the endoplasmic reticulum protein Sec61 $\alpha$ was not bound to the immunobeads, indicating that the immunoisolations of organelles were

Figure 7. Vti1a- $\beta$ copurified with clathrin-coated vesicles isolated from nerve terminals. Clathrin-coated vesicles $(C C V s)$ were isolated from synaptosomes with brain homogenate as the starting material. Highly enriched clathrin-coated vesicles were isolated from the high-speed pellet of lysed synaptosomes (Ficoll load) via the fractions Ficoll SN and $\mathrm{D}_{2} \mathrm{O}$ load. Vtila- $\beta$ copurified in parallel with the synaptic vesicle markers synaptobrevin $(S y b)$, synaptophysin $(S y p)$, and SCAMP in clathrin-coated vesicles. Clathrin light chain $(C L C)$ was highly enriched. Very low amounts of Vti1b were found in clathrin-coated vesicles.

\section{Vti1a- $\beta$ was enriched in synaptic vesicles}

Next, we wanted to distinguish between Vtila and the splice variant Vti1a- $\beta$ and localize them to different compartments within the nerve terminal by subcellular fractionation and immunoblotting. First, synaptic vesicles were purified according to Huttner et al. (1983). Synaptic vesicles (CPG3) were isolated from brain homogenate $(\mathrm{H})$ via the fractions synaptosomes (P2) and highspeed pellet of lysed synaptosomes (LP2) (Fig. 5). Vtila- $\beta$ copurified together with synaptic vesicles as indicated by the marker synaptobrevin in the fractions P2, LP2, and CPG3. The lower molecular weight ubiquitous Vti1a and the slightly larger brainspecific.

specific Vti1a- $\beta$ were both present in early fractions of the purification, such as $\mathrm{H}$ and $\mathrm{P} 1$. In contrast, only Vti1a- $\beta$ was found in the purified fractions LP2 and CPG3. These data indicate that Vti1a- $\beta$ was enriched in synaptic vesicles.

Vtilb was present throughout the purification but was not enriched in the CPG3 fraction. By comparing immunoblots of purified synaptic vesicles and known amounts of recombinant Vti1b and Vtila, it was estimated that synaptic vesicles contain at least 10 times less Vti1b than Vti1a- $\beta$ (data not shown).

To confirm that Vti1a- $\beta$ localized to synaptic vesicles, the CPG3 fraction was analyzed by immunogold electron microscopy. Vti1a antiserum specifically stained synaptic vesicles (Fig. 6B). The labeling intensities were low because the antisera were used at high dilutions to avoid background staining (Fig. 6C). The antiserum against the abundant synaptic vesicle protein synaptophysin gave a stronger staining (Fig. 6A). Only small structures representing 


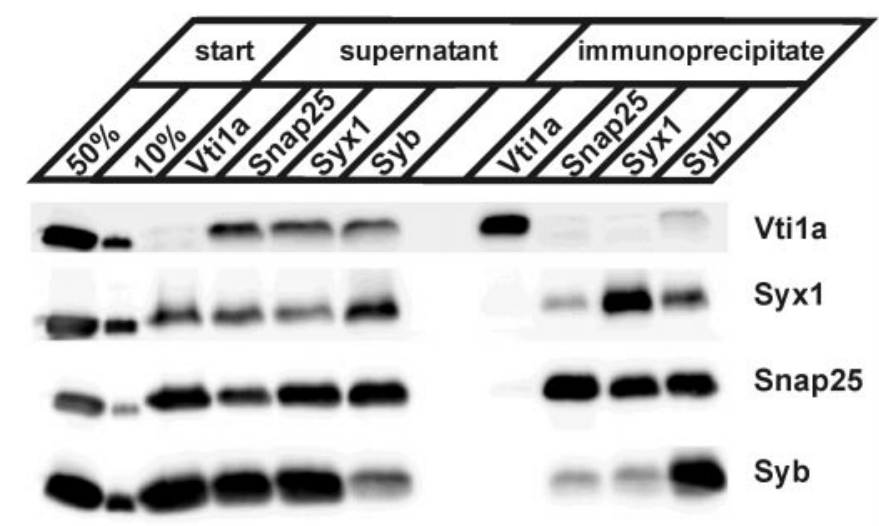

Figure 9. Vtila- $\beta$ was not found in the exocytic SNARE complex. SNARE complexes were isolated from Triton X-100 extracts of synaptosomes using antisera against Vti1a, SNAP-25, syntaxin 1 (Syxl), or synaptobrevin $(S y b)$. Vti1a antiserum did not coimmunoprecipitate syntaxin 1, SNAP-25, or synaptobrevin. SNAP-25, syntaxin 1, and synaptobrevin coimmunoprecipitated as a SNARE complex.

synaptic vesicles were decorated by Vti1a antiserum in the crude LP2 fraction; larger membranes were not labeled (data not shown). These data confirm that Vtila was specifically localized to synaptic vesicles.

\section{Vti1a- $\beta$ was enriched in clathrin-coated vesicles}

Next, we wanted to examine whether Vtila- $\beta$ is present on the synaptic vesicle membrane throughout the synaptic vesicle recycling pathway. The synaptic vesicle membrane is incorporated into the plasma membrane upon exocytosis and endocytosed via clathrin-coated vesicles. Synaptic vesicles are reformed either by uncoating of these clathrin-coated vesicles or via an endosomal intermediate (Hannah et al., 1999). Clathrin-coated vesicles were isolated from synaptosomes (Maycox et al., 1992). Clathrin light chain and the synaptic vesicle proteins synaptophysin and synaptobrevin were used as marker proteins for the enrichment of clathrin-coated vesicles (Fig. 7). Vti1a- $\beta$ coenriched in parallel with synaptophysin and synaptobrevin, indicating that Vti1a- $\beta$ was localized to clathrin-coated vesicles. Synaptophysin was less enriched than clathrin light chain because the major pool of synaptophysin is associated with synaptic vesicles. In contrast, less Vti1b was present on purified clathrin-coated vesicles compared with the starting material. Therefore, Vti1b was only a minor component of clathrin-

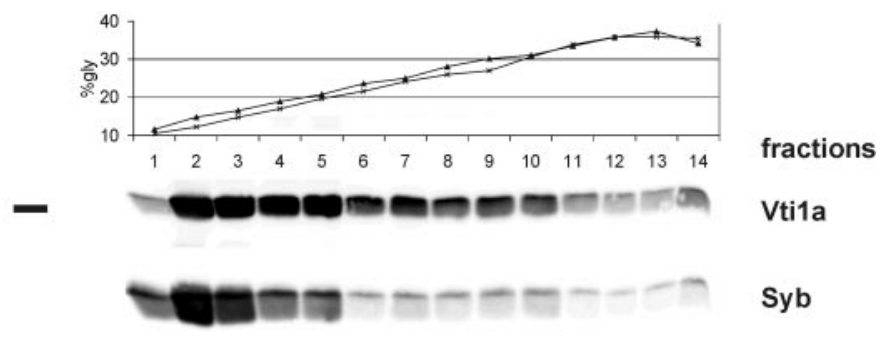

NSF $\alpha$-SNAP

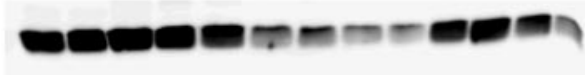

Vti1a

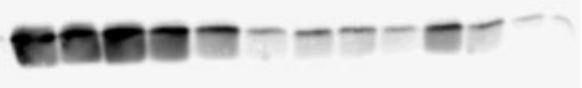

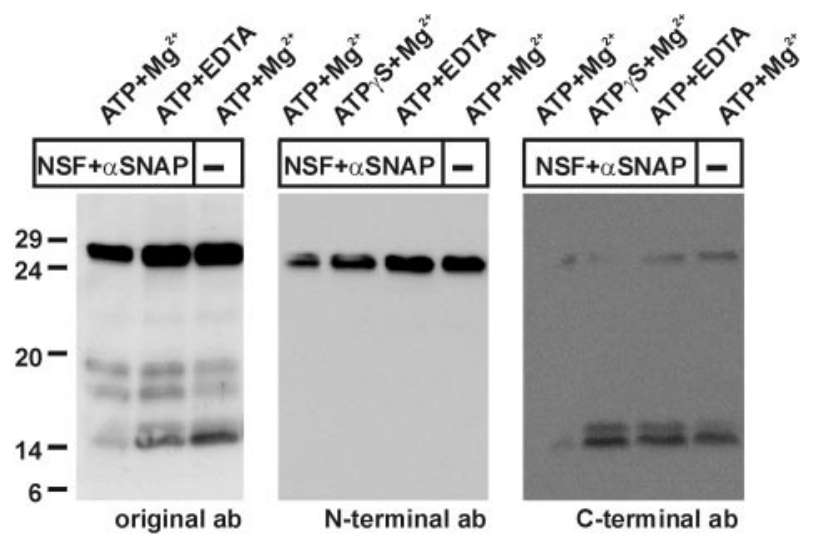

Figure 11. A C-terminal $14 \mathrm{kDa}$ fragment of Vti1a- $\beta$ with the SNARE motif was protease-protected under conditions of SNARE complex assembly but not disassembly. Detergent extracts from lysed synaptosomes (high-speed membrane fraction LP2) were incubated with NSF and $\alpha$-SNAP plus ATP + $\mathrm{Mg}^{2+}$ (disassembly of SNARE complexes), ATP $\gamma \mathrm{S}+\mathrm{Mg}^{2+}$, or ATP + EDTA (inhibition of disassembly). SNARE complexes remained assembled without addition of NSF and $\alpha$-SNAP. Fractions were incubated with trypsin and separated by SDS-PAGE. Immunoblots were developed with antisera against Vtila (left), against the N-terminal half of Vti1a (middle), or against the C-terminal half of Vtila (right).

coated vesicles in the nerve terminal. As shown previously (Maycox et al., 1992; Fischer von Mollard et al., 1994), rab3a and rab5 were deriched in clathrin-coated vesicles compared with the starting material of the last purification step $\left(\mathrm{D}_{2} \mathrm{O}\right.$ load $)$.

\section{Vti1a- $\beta$ was found on immunoisolated synaptic vesicles and endosomes}

By subcellular fractionation, we have shown that Vtila- $\beta$ was enriched in synaptic vesicles. To verify this finding, we used an immunoisolation procedure as an independent method to purify organelles. Antibodies against synaptobrevin, rab3a, or rab5 were coupled to Eupergit beads and used for isolation of organelles from a 50,000 $\times g$ supernatant of brain homogenate (Burger et al., 1989). Synaptic vesicles are the predominant organelle in this starting material because each neuron forms $\sim 1000$ synapses containing numerous synaptic vesicles. Golgi membranes, clathrin-coated vesicles, endocytic intermediates, and endosomes are much less abundant. Synaptobrevin as a membrane protein is present on synaptic vesicle membranes throughout their life cycle, i.e., is present on mature synaptic vesicles as well as on membranes during the biogenesis and in the process of recycling, such as clathrin-coated vesicles, endocytic intermediates, and endosomes. Rab3a and rab5 have overlapping but not identical distributions. Rab3a is enriched in synaptic vesicles but absent from clathrin-coated vesicles and Golgi membranes. Rab5 is found predominantly on endosomes but also on a subpopulation of synaptic vesicles. Almost all Vti1a- $\beta$ containing organelles present in the starting material were bound to synaptobrevin beads, as well as to rab3a-beads (Fig. 8). Organelles containing synaptobrevin were quantitatively isolated by synaptobrevin beads and rab3a beads. These data confirm that Vtila- $\beta$ was localized to synaptic vesicles. Less Vti1a- $\beta$-containing organelles were isolated with rab5 beads. Some Vti1a- $\beta$, as well as some synaptobrevin, was not bound to rab5 beads because some synaptic vesicles do not contain rab5. These data indicate that Vtila- $\beta$ together with synaptobrevin was present on synaptic vesicle membranes throughout their life cycle.

A fraction of Vti1b-containing organelles were immunoisolated with synaptobrevin, rab3a, and rab5 beads. More than $50 \%$ of Vti1b remained unbound in these immunoisolations. Because synaptic vesicles are so abundant in the starting material, these data indicate that Vti1b was present on synaptic vesicles at lower concentrations, as well as on other membranes not connected to the synaptic vesicle pathway at higher concentrations.
Figure 10. Vtila- $\beta$ was part of a SNARE complex that bound NSF and $\alpha$-SNAP. Detergent extracts from lysed synaptosomes (high-speed membrane fraction LP2) were incubated without additions (-) or with NSF and $\alpha$-SNAP and separated on a glycerol gradient. Fractions were analyzed by SDS-PAGE and immunoblotting. A subfraction of Vti1a- $\beta$ and synaptobrevin $(S y b)$ were shifted to denser fractions 11-13 in the presence of NSF and $\alpha$-SNAP. 


\section{Vti1a- $\beta$ did not coimmunoprecipitate with the exocytic SNARE complex}

Because we identified Vti1a- $\beta$ as a synaptic vesicle protein, we wanted to determine whether Vti1a- $\beta$ was in a complex with the SNAREs required for fusion of synaptic vesicles with the plasma membrane. SNARE complexes were immunoprecipitated from Triton X-100 extracts of synaptosomes using antibodies against Vtila, SNAP-25, syntaxin 1, and synaptobrevin, respectively. SNAREs in these immunoprecipitates were detected by immunoblotting (Fig. 9). Syntaxin 1, SNAP-25, and synaptobrevin were not present in the Vtila immunoprecipitates, although Vtila- $\beta$ was quantitatively removed from the extract. Vti1a antiserum coimmunoprecipitated syntaxin 6 as described by Xu et al. (1998), indicating that the Vtila antiserum was able to immunoprecipitate a SNARE complex (data not shown). The three SNAREs of the exocytic SNARE complex were coimmunoprecipitated with antibodies against synaptobrevin, syntaxin 1, or SNAP-25, indicating that SNARE complexes were present under our experimental conditions. Vtila- $\beta$ was not coimmunoprecipitated by antibodies against syntaxin 1 and SNAP-25. These data indicate that Vti1a- $\beta$ was not part of the exocytic SNARE complex. A small amount of Vtila- $\beta$ was present in the synaptobrevin immunoprecipitates. It is likely that this interaction is weak or nonspecific because synaptobrevin was absent from Vtila immunoprecipitates.

\section{Vti1a- $\beta$ was part of an NSF- and $\alpha$-SNAP-containing SNARE complex in nerve terminals}

After establishing that Vti1a- $\beta$ was not part of the exocytic SNARE complex, we wanted to determine whether Vtila- $\beta$ was part of a novel SNARE complex in nerve terminals. SNARE complexes have the characteristic ability to bind NSF and $\alpha$-SNAP and form a $20 \mathrm{~S}$ complex. NSF disassembles these complexes in the presence of ATP and $\mathrm{Mg}^{2+}$ (Söllner et al., 1993b). Two different approaches were taken to study whether Vti1a- $\beta$ in nerve terminals exists in a SNARE complex, which can bind NSF and $\alpha$-SNAP and is disassembled by NSF. First, detergent extracts from the highspeed pellet of lysed synaptosomes (LP2) containing mostly synaptic vesicles were incubated with NSF and $\alpha$-SNAP under conditions that favor formation of a $20 \mathrm{~S}$ complex or without addition of NSF and $\alpha$-SNAP. These extracts were separated on a glycerol density gradient, and Vtila- $\beta$ and synaptobrevin were identified by immunoblotting (Fig. 10). Significantly more Vti1a- $\beta$ and synaptobrevin were found in the higher density fractions 11-14 in the presence of NSF and $\alpha$-SNAP compared with the extract without additions. These data indicate that a subfraction of Vti1a- $\beta$ was present in a SNARE complex that bound NSF and $\alpha$-SNAP.

In the second approach, we used the observation that the fourhelix bundle in the assembled SNARE complex (core complex) is much more protease-resistant than the rest of the molecules or the disassembled SNAREs (Fasshauer et al., 1998a; Poirier et al., 1998). Therefore, we looked for a protease-resistant Vtila- $\beta$ fragment under conditions in which a SNARE complex is stable. Detergent extracts from the high-speed pellet of lysed synaptosomes (LP2) were treated with trypsin under different conditions: SNARE complex disassembly by addition of NSF, $\alpha$-SNAP, ATP, and $\mathrm{Mg}^{2+}$ (Fig. 11A, first lane); inhibition of disassembly in the presence of NSF and $\alpha$-SNAP by EDTA (second lane); or without additions, maintaining SNARE complexes (third lane). Vtila- $\beta$ was detected in these fractions by immunoblotting. A protease-resistant Vtila- $\beta$ fragment of $14 \mathrm{kDa}$ was identified in fractions favoring SNARE complex formation but not under conditions of SNARE complex disassembly. Next, we wanted to determine whether the 14 $\mathrm{kDa}$ fragment was part of the $\mathrm{N}$-terminal or $\mathrm{C}$-terminal half of Vtila- $\beta$ with the SNARE motif. The antiserum against Vtila was affinity-purified with an immobilized GST fusion with either the amino acid residues 1-114 of Vti1a or residues 115-192. The resulting antibodies were specific for the $\mathrm{N}$-terminal or $\mathrm{C}$-terminal part of Vti1a, respectively (data not shown). SNARE complex disassembly was also inhibited by addition of ATP $\gamma \mathrm{S}$ to exclude effects of EDTA. The $14 \mathrm{kDa}$ fragment was only recognized by the antiserum specific for the C-terminal half (Fig. 11C) but not by the antiserum against the N-terminal part (Fig. 11B). These data indicate that the $\mathrm{C}$-terminal part of Vtila- $\beta$ with the SNARE motif was protected from proteases only under conditions in which SNARE complexes are stable. Therefore, Vtila- $\beta$ was part of a novel SNARE complex in nerve terminals.

\section{DISCUSSION}

We identified Vti1a- $\beta$ as a brain-specific splice variant of Vtila. Our results show that the brain-specific Vtila- $\beta$ but not the ubiquitous Vtila is enriched in synaptic vesicles and nerve terminalderived clathrin-coated vesicles. Vtila- $\beta$ and synaptobrevin were isolated to a similar degree by rab5 beads used to immunoisolate endosomes and rab5-containing synaptic vesicles. Our data indicate that both synaptobrevin and Vti1a- $\beta$ are integral components of the synaptic vesicle membrane throughout the vesicle life cycle. Vtilb was found at low concentrations on synaptic vesicles and nerve terminal-derived clathrin-coated vesicles. These data indicate that Vtilb may only be a minor component or only present on a subpopulation of synaptic vesicles.

The brain-specific Vti1a- $\beta$ had an insertion of seven amino acid residues at position 114 of the ubiquitous Vti1a. This insertion is located at the beginning of an evolutionary conserved predicted $\alpha$-helix. The domain that forms the SNARE-interacting helix according to sequence alignments (Fasshauer et al., 1998b) is close by and starts at amino acid residue 132 . The close proximity of the brain-specific insert to the SNARE motif raises the possibility that binding of SNARE partners is influenced by these additional amino acid residues. The insertion may be important for sorting of Vtila- $\beta$ to synaptic vesicles. Consensus signals for targeting of proteins to synaptic vesicles are still unknown. However, it was found that the SNARE motif of synaptobrevin is important for localization to synaptic-like microvesicles (SLMV) in the neuroendocrine cell line PC12 (Grote et al., 1995).

Two lines of evidence demonstrated that Vti1a- $\beta$ was present in a SNARE complex, which was disassembled by the addition of NSF and $\alpha$-SNAP in nerve terminals. First, Vtila- $\beta$ moved to denser fractions in a glycerol gradient upon the addition of NSF and $\alpha$-SNAP, suggesting the presence of Vtila- $\beta$ in a SNARE complex that bound NSF and $\alpha$-SNAP. In addition, a C-terminal fragment of Vtila- $\beta$ with the SNARE motif was protected from protease digestion only under conditions in which SNARE complexes are stable but not when they are disassembled. Although enriched on synaptic vesicles Vtila- $\beta$ coimmunoprecipitated with neither syntaxin 1 nor with SNAP-25. These data indicate that Vtila- $\beta$ does not function in the SNARE complex required for regulated exocytosis. These results provide further evidence for the specific formation of SNARE complexes in vivo. Although it was observed that noncognate SNARE complexes can form in vitro and have similar properties as cognate SNARE complexes (Fasshauer et al., 1999; Yang et al., 1999), these noncognate SNARE complexes could not be isolated by coimmunoprecipitation from cell extracts (Fasshauer et al., 1999). Because we identified a novel, Vti1a- $\beta$ containing SNARE complex within the nerve terminal, our data also indicate that a second membrane fusion step is required at some point in the life cycle of synaptic vesicles and that Vtila- $\beta$ functions in this step.

Vtila- $\beta$ may be required for a fusion step during synaptic vesicle recycling. Synaptic vesicle membranes can undergo several hundred rounds of exocytosis and reloading with neurotransmitter. Therefore, it is critical that the protein composition of synaptic vesicles is maintained or restored during recycling. Several models have been suggested for synaptic vesicle recycling (Cremona and De Camilli, 1997). Synaptic vesicles may transiently fuse with the plasma membrane, release their content via the fusion pore, and reseal. This kiss-and-run mechanism may be favored under conditions of strong stimulation and avoids mixing of synaptic vesicle proteins with plasma membrane proteins (Alés et al., 1999). Clathrin-coated vesicles are intermediates in synaptic vesicle recycling, as was demonstrated using several different approaches (Mill- 
er and Heuser, 1984; van der Bliek and Meyerowitz, 1991). However, it is still under debate whether uncoating of clathrin-coated vesicles results directly in synaptic vesicles without any further intermediates and without fusion steps (Takei et al., 1996; Murthy and Stevens, 1998) or whether an endosomal intermediate is involved. Nerve terminals contain early endosomes, as indicated by the presence of the early endosome marker protein rab5 (Fischer von Mollard et al., 1994). According to a model with a sorting compartment, uncoated clathrin-coated vesicles would fuse with endosomes requiring a SNARE complex. Vti1a- $\beta$ may be involved in this fusion step. Synaptic vesicles are generated by budding from these endosomes. Both pathways could exist in parallel. Synaptic vesicles may reform from clathrin-coated vesicles as long as they have the correct protein composition. A passage through the endosome may be required as a sorting step to restore the protein composition of synaptic vesicles. Budding of SLMV has been reconstituted in vitro with $\mathrm{PC} 12$ cells from both an endosomal compartment and a subplasmalemmal compartment still connected with the plasma membrane. Synaptic vesicle proteins accumulate in a subplasmalemmal tubulocisternal compartment that is devoid of the endosomal marker transferrin receptor. SLMV budding from this compartment is dependent on clathrin, AP-2, and other proteins required for formation of clathrin-coated vesicles (Schmidt and Huttner, 1998; Shi et al., 1998). On the other hand, SLMV are formed from endosomes isolated from PC12 cells (Clift-O'Grady et al., 1998). The resulting SLMV are devoid of transferrin receptor present in the donor compartment. This budding step is dependent on the adaptor complex AP-3. The transport of endocytosed synaptobrevin to early endosomes and the budding of SLMV from tubular extensions of early endosomes has been observed in PC12 cells using immunoelectron microscopy (de Wit et al., 1999)

It is possible that Vtila- $\beta$ or Vtilb have a role in the biogenesis of synaptic vesicles. The biogenesis of synaptic vesicles is still unclear. Most data indicate that synaptic vesicle proteins leave the TGN in vesicles destined for the constitutive secretory pathway (Hannah et al., 1999). These vesicles are transported through the axon by fast axonal transport. Mature synaptic vesicles are formed after several rounds of constitutive exocytosis and recycling via an endosome. In yeast, Vti1p is not involved in constitutive secretion and does not bind the plasma membrane t-SNAREs Sso1p/Sso2p. In contrast, yeast Vtilp binds all endosomal, vacuolar-lysosomal, and Golgi t-SNAREs (Fischer von Mollard et al., 1997; Holthuis et al., 1998). Therefore, a role in constitutive exocytosis seems unlikely.

So far we do not know the SNARE partners of Vti1a- $\beta$ and Vti1b in the nerve terminal. Candidates would be endosomal SNARE proteins. Three R-SNAREs have been localized to the endosomal system: endobrevin/ vesicle-associated membrane protein -8 (VAMP-8), which is expressed at low levels in brain (Advani et al., 1998; Wong et al., 1998), VAMP-7/TI-VAMP (Advani et al., 1999), and VAMP-4 (Steegmaier et al., 1999). Recently, endogenous VAMP-7/TI-VAMP has been localized to somatodendritic tubules and vesicles in cultured neurons but not to nerve terminals (Coco et al., 1999). Therefore, VAMP-7 and Vti1a- $\beta$ do not colocalize in synapses. Q-SNAREs identified in TGN or endosomal membranes are syntaxin 6 (Simonsen et al., 1999), syntaxin 12/13 (Prekeris et al., 1998; Tang et al., 1998b), syntaxin 7, syntaxin 8 (Wang et al., 1997; Prekeris et al., 1999), syntaxin 11, which is expressed at low levels in brain (Valdez et al., 1999), and syntaxin 10 (Tang et al., 1998a).

The localization of Vti1a- $\beta$ to synaptic vesicles suggests that this SNARE is more specialized for certain trafficking steps and may only bind to a subset of SNARE proteins required for these trafficking steps in vivo than the promiscuous yeast Vti1p.

\section{REFERENCES}

Advani RJ, Bae HR, Bock JB, Chao DS, Doung YC, Prekeris R, Yoo JS, Scheller RH (1998) Seven novel mammalian SNARE proteins localize to distinct membrane compartments. J Biol Chem 273:10317-10324. Advani RJ, Yang B, Prekeris R, Lee KC, Klumperman J, Scheller RH
(1999) VAMP-7 mediates vesicular transport from endosomes to lysosomes. J Cell Biol 146:765-775.

Alés E, Tabares L, Poyato JM, Valero V, Lindau M, de Toledo GA (1999) High calcium concentrations shift the mode of exocytosis to the kiss-andrun mechanism. Nat Cell Biol 1:40-44.

Barnstable CJ, Hofstein R, Akagawa K (1985) A marker of early amacrine cell development in rat retina. Dev Brain Res 20:286-290.

Bruns D, Engers S, Yang C, Ossig R, Jeromin A, Jahn R (1997) Inhibition of transmitter release correlates with the proteolytic activity of tetanus toxin and botulinus toxin A in individual cultured synapses of Hirudo medicinalis. J Neurosci 17:1898-1910.

Burger PM, Mehl E, Cameron PL, Maycox PR, Baumert M, Lottspeich F, De Camilli P, Jahn R (1989) Synaptic vesicles immunoisolated from rat cerebral cortex contain high levels of glutamate. Neuron 3:715-720.

Clift-O'Grady L, Desnos C, Lichtenstein Y, Faúndes V, Horng JT, Kelly RB (1998) Reconstitution of synaptic vesicle biogenesis from PC12 cell membranes. Methods 16:150-159.

Coco S, Raposo G, Martinez S, Fontaine JJ, Takamori S, Zahraoui A, Jahn R, Matteoli M, Louvard D, Galli T (1999) Subcellular localization of tetanus neurotoxin-insensitive vesicle-associated membrane protein (VAMP)/VAMP7 in neuronal cells: evidence for a novel membrane compartment. J Neurosci 15:9803-9812.

Cremona O, De Camilli P (1997) Synaptic vesicle endocytosis. Curr Opin Neurobiol 7:323-330.

de Wit H, Lichtenstein Y, Geuze HJ, Kelly RB, van der Sluijs P, Klumperman J (1999) Synaptic vesicles from by budding from tubular extensions of sorting endosomes in PC12 cells. Mol Biol Cell 10:4163-4176.

Fasshauer D, Eliason W, Brunger A, Jahn R (1998a) Identification of a minimal core of the synaptic SNARE complex sufficient for reversible assembly and disassembly. Biochemistry 37:10354-10362.

Fasshauer D, Sutton RB, Brunger AT, Jahn R (1998b) Conserved structural features of the synaptic fusion complex: SNARE proteins reclassified as Q- and R-SNAREs. Proc Natl Acad Sci USA 95:15781-15786.

Fasshauer D, Antonin W, Margittai M, Pabst S, Jahn R (1999) Mixed and non-cognate SNARE complexes. J Biol Chem 274:15440-15446.

Fischer von Mollard G, Stevens TH (1998) A Human homolog can functionally replace the yeast v-SNARE Vtilp in two vesicle transport pathways. J Biol Chem 273:2624-2630.

Fischer von Mollard G, Stevens TH (1999) The Saccharomyces cerevisiae v-SNARE Vti1p is required for multiple membrane transport pathways to the vacuole. Mol Biol Cell 10:1719-1732.

Fischer von Mollard G, Stahl B, Walch-Solimena C, Takei K, Daniels L, Khokhlatchev A, De Camilli P, Südhof TC, Jahn R (1994) Localization of rab5 to synaptic vesicles identifies endosomal intermediate in synaptic recycling pathway. Eur J Cell Biol 65:319-326.

Fischer von Mollard G, Nothwehr SF, Stevens TH (1997) The yeast v-SNARE Vtilp mediates two vesicle transport pathways through interactions with the t-SNAREs Sed5p and Pep12p. J Cell Biol 137:1511-1524.

Grote E, Hao JC, Bennett MK, Kelly RB (1995) A targeting signal in VAMP regulating transport to synaptic vesicles. Cell 81:581-589.

Hannah M, Weiss U, Huttner WB (1998) Differential extraction of proteins from paraformaldehyde-fixed cells: lessons from synaptophysin and other membrane proteins. Methods 16:170-181.

Hannah MJ, Schmidt AA, Huttner WB (1999) Synaptic vesicle biogenesis. Annu Rev Cell Dev Biol 15:733-798.

Hanson PI, Otto H, Barton N, Jahn R (1995) The $N$-ethylmaleimidesensitive fusion protein and alpha-SNAP induce a conformational change in syntaxin. J Biol Chem 270:16955-16961.

Holthuis JCM, Nichols BJ, Dhruvakumar S, Pelham HRB (1998) Two syntaxin homologues in the TGN/endosomal system in yeast. EMBO J 17:113-126.

Huttner WB, Schiebler W, Greengard P, De Camilli P (1983) Synapsin I (protein I) a nerve terminal specific phosphoprotein. Its association with synaptic vesicles studied in a highly purified synaptic vesicle preparation. J Cell Biol 96:1374-1388.

Jahn R, Sudhof T (1999) Membrane fusion and exocytosis. Annu Rev Biochem 68:863-911.

Jahn R, Schiebler W, Ouitmet C, Greengard P (1985) A 38,000-dalton membrane protein (p38) present in synaptic vesicles. Proc Natl Acad Sci USA 82:4137-4141.

Lupashin VV, Pokrovskaya ID, McNew JA, Waters MG (1997) Characterization of a novel yeast SNARE protein implicated in Golgi retrograde traffic. Mol Biol Cell 8:2659-2676.

Matteoli M, Takei K, Cameron R, Hurlbut P, Johnston PA, Südhof TC, Jahn R, De Camilli P (1991) Association of rab3A with synaptic vesicles at late stages of the secretory pathway. J Cell Biol 115:625-633.

Maycox PR, Link E, Reetz A, Morris SA, Jahn R (1992) Clathrin-coated vesicles in nervous tissue are involved primarily in synaptic vesicle recycling. J Cell Biol 118:1379-1388.

Miller TM, Heuser JE (1984) Endocytosis of synaptic vesicle membrane at the frog neuromuscular junction. J Cell Biol 98:685-698.

Mugnaini E, Dahl AL (1983) Zinc-aldehyde fixation for light-microscopic immunocytochemistry of nervous tissues. J Histochem Cytochem 31:1435-1438. 
Murthy VN, Stevens CF (1998) Synaptic vesicles retain their identity through the endocytic cycle. Nature 392:497-501.

Poirier M, Hao J, Malkus P, Chan C, Moore M, King D, Bennett M (1998) Protease resistance of syntaxin.SNAP-25.VAMP complexes. Implications for assembly and structure. J Biol Chem 273:11370-11377.

Prekeris R, Klumperman J, Chen YA, Scheller RH (1998) Syntaxin 13 mediates cycling of plasma membrane proteins via tubulovesicular recycling endosomes. J Cell Biol 143:957-971.

Prekeris R, Yang B, Oorschot V, Klumperman J, Scheller RH (1999) Differential roles of syntaxin 7 and syntaxin 8 in endosomal trafficking. Mol Biol Cell 10:3891-3908.

Rosenmund C, Feltz A, Westbrook G (1995) Synaptic NMDA receptor channels have a low open probability. J Neurosci 15:2788-2795.

Rossi G, Salminen A, Rice L, Brunger A, Brennwald P (1997) Analysis of a yeast SNARE complex reveals remarkable similarity to the neuronal SNARE complex and a novel function for the C-terminus of the SNAP-25 homolog, Sec9. J Biol Chem 272:16610-16617.

Rothman J (1994) Mechanism of intracellular protein transport. Nature 372:55-63.

Schmidt A, Huttner WB (1998) Biogenesis of synaptic-like microvesicles in perforated PC12 cells. Methods 16:160-169.

Shi G, Faúndez V, Roos J, Dell'Angelica EC, Kelly RB (1998) Neuroendocrine synaptic vesicles are formed in vitro by both clathrin-dependent and clathrin-independent pathways. J Cell Biol 143:947-955.

Simonsen A, Gaullier JM, D’Arrigo A, Stenmark H (1999) The rab5 effector EEA1 interacts directly with syntaxin 6. J Biol Chem 274:28857-28860.

Söllner T, Bennett MK, Whiteheart SW, Scheller RH, Rothman JE (1993a) A protein assembly-disassembly pathway in vitro that may correspond to sequential steps of synaptic vesicle docking, activation, and fusion. Cell 75:409-418.

Söllner T, Whiteheart SW, Brunner M, ErdjumentBromage H, Geromanos S, Tempst P, Rothman JE (1993b) SNAP receptors implicated in vesicle targeting and fusion. Nature 362:318-324.

Steegmaier M, Klumperman J, Foletti DL, Yoo JS, Scheller RH (1999) Vesicle-associated membrane protein 4 is implicated in trans-Golgi network vesicle trafficking. Mol Biol Cell 10:1957-1972.

Sutton RB, Fasshauer D, Jahn R, Brunger AT (1998) Crystal structure of a SNARE complex involved in synaptic exocytosis at $2.4 \AA$ resolution. Nature 395:347-353.

Takei K, Mundigl O, Daniell L, De Camilli P (1996) The synaptic vesicle cycle: a single vesicle budding step involving clathrin and dynamin. J Cell Biol 131:1237-1250.

Tang BL, Low DYH, Tan AEH, Hong W (1998a) Syntaxin 10: a member of the syntaxin family localized to the trans-Golgi network. Biochem Biophys Res Commun 242:345-350.

Tang BL, Tan AEH, Lim LK, Lee SS, Low DYH, Hong W (1998b) Syntaxin 12, a member of the syntaxin family localized to the endosome. J Biol Chem 273:6944-6950.

Ungermann C, Fischer von Mollard G, Jensen ON, Margolis N, Stevens TH, Wickner W (1999) Three v-SNAREs and two t-SNAREs, present in a pentameric cis-SNARE complex on isolated vacuoles, are essential for homotypic fusion. J Cell Biol 145:1435-1442.

Valdez AC, Cabaniols JP, Brown MJ, Roche PA (1999) Syntaxin 11 is associated with SNAP-23 on late endosomes and the trans-Golgi network. J Cell Sci 112:845-854

van der Bliek AM, Meyerowitz EM (1991) Dynamin-like protein encoded by the Drosophila shibire gene associated with vesicular traffic. Nature 351:411-414.

Wang H, Frelin L, Pevsner J (1997) Human syntaxin7: a Pep12p/Vps6p homologue implicated in vesicle trafficking to lysosomes. Gene 199:39-48.

Wessel D, Flügge UI (1984) A method for the quantitative recovery of proteins in dilute solutions in the presence of detergents and lipids. Anal Biochem 138:141-143.

Wong SH, Zhang T, Xu Y, Subramaniam VN, Griffiths G, Hong W (1998) Endobrevin, a novel synaptobrevin/VAMP-like protein preferentially associated with the early endosome. Mol Biol Cell 9:1549-1563.

Xu, Y, Wong SH, Tang BL, Subramaniam VN, Zhang T, Hong W (1998) A 29-kilodalton Golgi soluble $N$-ethylmaleimide-sensitive factor attachment protein receptor (Vti1-rp2) implicated in protein trafficking in the secretory pathway. J Biol Chem 273:21783-21789.

Yang B, Gonzalez L, Prekaris R, Steegmaier M, Advani RJ, Scheller RH (1999) SNARE proteins are not selective. Implications for membrane fusion specificity. J Biol Chem 274:5649-5653. 